\title{
Heat and Mass Transfer of Williamson Nanofluid with the Effects of Viscous Dissipation and Chemical Reaction
}

\author{
Ganji Narender $^{*}$, Nagula Manjula ${ }^{2}$, Kamatam Govardhan $^{3}$, M. N. Rajashekar ${ }^{4}$ \\ ${ }^{1}$ Department of Humanities \& Science (Mathematics), CVR College of Engineering, Hyderabad, Telangana State, India \\ ${ }^{2}$ Department of Humanities \& Science (Mathematics), Sreenidhi Institute of Science and Technology, Hyderabad, India \\ ${ }^{3}$ Department of Mathematics, GITAM University Hyderabad, Telangana State, India \\ ${ }^{4}$ Department of Mathematics, JNTUH College of Engineering Jagtial, Telangana State, India
}

Corresponding Author Email: gnriimc@gmail.com

https://doi.org/10.18280/ti-ijes.630115

Received: 2 April 2019

Accepted: 21 April 2019

\section{Keywords:}

Williamson nanofluid, stretching surface, viscous dissipation, chemical reaction parameter, heat and mass transfer

\begin{abstract}
D A numerical analysis is performed for the mathematical model of boundary layer flow of nanofluids. Heat and mass transfer are analyzed for an incompressible fluid with viscous dissipations and chemical reaction past a stretching surface. An appropriate set of similarity transformations are used to transform the governing partial differential equations (PDEs) into a system of nonlinear ordinary differential equations (ODEs). The resulting system of ODEs is solved numerically by using Adams-Moultan method along with shooting method. Furthermore, we compared our results with the existing results for especial cases which are in an excellent agreement. The numerical values obtained for various non-dimensional physical quantities together with velocity, temperature and concentration profiles are presented through graphs and tables. The effects of different physical parameters on the flow and heat transfer characteristics are discussed in detail.
\end{abstract}

\section{INTRODUCTION}

The boundary layer is the region adjacent to the surface of an object around which the fluid is flowing. Flow of the boundary layer play an important role in fluid mechanics and has been extensively studied in the literature. Prandtl [1] was the first who presented the concept of boundary layer. Makinde and Motsumi [2] studied the boundary layer flow of nanofluids over a continuously moving surface. Ibrahim and Makinde [3] investigated the thermal boundary layer flow with effects of double stratification over a vertical sheet. In addition to that in a series of article, Makinde [4, 5] studied the boundary layer flow of nanofluids passing over a at plate. They further analyzed the impacts of viscous dissipation and Newtonian heating for various types of geometry including permeable surface. The main purpose of their study is the computation of mathematical models of nanofluid over steady/unsteady stretching sheet. The boundary layer flow over a moving surface have a number of applications in engineering and industrial fields. Sakiadis et al. [6] presented the concept of the boundary layer flow through a stretching surface.

The small solid particle is known as nanoparticle, these nanoparticles ranges from 1-100 nanometers in size. The nanofluid is defined as the homogenous mixture of the base fluid and nanoparticle. In 1995, Choi [7] in his pioneering work introduced the terminology of nanofluids. Since then an extensive research is carried out on this topic by many researchers due to its potential industrial applications. In the current progress in the field of science and technology, the nanotechnology has a wide range of applications in different fields. In the last couple of decades, the development in nanotechnology is exponentially increasing. The effects of nanoparticle migration on force convection of nanofluid in a channel are studied for alumina [8] critical analysis of thermophysical characteristics of nanofluids are investigated by Khanafer and Vafai [9].

The heat transfer in the boundary layer flow of nanofluid has been an interesting topic for researchers. Masuda et al. [10] found that nanofluids are enhancing thermal conductivity, they further noted the potential applications of nanofluid in nuclear technology. They studied the characteristics of nanofluid by dispersing ultra-_ne particles in base fluid with varying viscosity and thermal conductivity. Buongiorno [11] developed a model with analytic solution for convective heat transfer in a Brownian diffusion of nanofluid. He observed the effects of diffusion and thermophoresis in nanofluid. A cavity ow with heat transfer and entropy generation are analyzed by Z. Mehrez et al. [12].

Viscous dissipation is unavoidable in case of flow field in high gravitational field. Viscous flow past a nonlinearly stretching sheet was deliberated by Vajravelu [13]. For external natural convention flow over a stretching medium, the impact of viscous dissipation was also studied by Mollendro and Gebhart [14], whereas the impact of viscous dissipation and Joule heating on the forced convection flow with thermal radiation was presented by Duwairi [15].

In this section we review the work S. Nadeen et al. [16] and is extended for numerical analysis of heat and mass transfer by taking additional effects of viscous dissipation and chemical reaction parameter. 


\section{PROBLEM DESCRIPTION AND MATHEMATICAL FORMULATION}

Let us consider the numerical investigation of MHD boundary layer flow of an incompressible Williamson nanofluid. The flow is two-dimensional past a stretching surface with porous medium. The plate has been stretched with velocity $u=a x,(a>0)$ along $x$-axis. The temperature at surface is $T_{w}, U_{w}, C_{w}$ represent fluid velocity, nanoparticle concentration at surface respectively. The general equations for nanofluid are given by Buongiorno [11]

$\frac{\partial u}{\partial x}+\frac{\partial v}{\partial x}=0$

$u \frac{\partial \mathrm{u}}{\partial \mathrm{x}}+\mathrm{v} \frac{\partial \mathrm{v}}{\partial \mathrm{y}}=v \frac{\partial^{2} u}{\partial y^{2}}+\sqrt{2} v \frac{\partial \mathrm{u}}{\partial \mathrm{y}} \frac{\partial^{2} u}{\partial y^{2}}$

$u \frac{\partial \mathrm{T}}{\partial \mathrm{x}}+\mathrm{v} \frac{\partial \mathrm{T}}{\partial \mathrm{y}}=\alpha_{m} \frac{\partial^{2} T}{\partial y^{2}}+\tau\left(D_{B}\left(\frac{\partial \mathrm{T}}{\partial \mathrm{y}} \frac{\partial \mathrm{C}}{\partial \mathrm{y}}\right)+\frac{D_{T}}{T_{\infty}}\left(\frac{\partial \mathrm{T}}{\partial \mathrm{y}}\right)^{2}\right)+$

$\frac{v}{(\rho c)_{f}}\left(\frac{\partial u}{\partial y}\right)^{2}$

$u \frac{\partial \mathrm{C}}{\partial \mathrm{x}}+\mathrm{v} \frac{\partial \mathrm{C}}{\partial \mathrm{y}}=D_{B}\left(\frac{\partial \mathrm{C}}{\partial \mathrm{y}}\right)^{2}+\frac{D_{T}}{T_{\infty}} \frac{\partial^{2} T}{\partial y^{2}}-k_{0} C$,

The associated boundary conditions:

$\left.\begin{array}{c}u=U_{w}(x)=a x, T=T_{w}, C=C_{w} \text { at } y=0, \\ u=0, T \rightarrow T_{\infty}, C \rightarrow C_{\infty} \text { as } y \rightarrow \infty\end{array}\right\}$

\section{DIMENSIONLESS FORM OF THE GOVERNING EQUATIONS}

In order to obtain the solution of the problem, first of all system of Eqns. (1)-(4) together with the boundary conditions (5) is converted into the dimensionless form by using suitable similarity transformation. The following similarity transformation as defined in [16] has been used.

$\eta=y \sqrt{\frac{a}{v}}, \psi=\sqrt{a v} x f(\eta), \quad \theta(\eta)=\frac{T-T_{=}}{T_{w}-T_{\infty}}$,

$\beta(\eta)=\frac{C-C_{\infty}}{C_{w}-C_{\infty}}$.

The continuity Eq. (1) is identically satisfied for the stream function $\psi(x, y)$.

The velocity components are given by:

$u=\frac{\partial \psi}{\partial y}, v=-\frac{\partial \psi}{\partial x}$

Using the similarity transformation from Eq. (11) in momentum Eq. (2), energy Eq. (3) and concentration Eq. (4) along the boundary conditions (5) we get the following system of ODEs:

$f^{\prime \prime \prime}+f f^{\prime \prime}-\left(f^{\prime}\right)^{2}+\lambda f^{\prime \prime} f^{\prime \prime \prime}=0$

$\frac{\theta^{\prime \prime}}{P r}+f \theta^{\prime}+\frac{N c}{L e} \theta^{\prime} \beta^{\prime}+\frac{N c}{L e \times N_{b t}}\left(\theta^{\prime}\right)^{2}+E c\left(f^{\prime \prime}\right)^{2}=0$

$\beta^{\prime \prime}+\operatorname{Sef} \beta^{\prime}+\frac{1}{N_{b t}} \theta^{\prime \prime}-\operatorname{Le\gamma } \beta=0$
The transformed BCs in the model problem are:

$$
\left.\begin{array}{c}
f^{\prime}(0)=1, f(\theta)=0, \theta(0)=1, \beta(0)=1 \text {, at } \eta=0, \\
f^{\prime}(\infty) \rightarrow 0, \theta(\infty) \rightarrow 0, \beta(\infty) \rightarrow 0 \text { as } \eta \rightarrow \infty
\end{array}\right\}
$$

The associated parameters appearing in the modeled problem are:

$$
\begin{gathered}
\lambda=\Gamma x \sqrt{\frac{2 a^{3}}{v}}, \operatorname{Pr}=\frac{v}{\alpha}, L e=\frac{\alpha}{D_{B}}, S e=\frac{v}{D_{B}}, N_{b t}=\frac{D_{B} T_{\infty}\left(C_{\infty}-C_{m}\right)}{D_{T} v T_{\infty}\left(T_{w}-T_{\infty}\right)}, \\
\begin{array}{c}
N b=\frac{\tau D_{B}\left(C_{w}-C_{\infty}\right)}{v}, E c=\frac{u_{w}^{2}}{\rho_{f}\left(\left(T_{w}-T_{\infty}\right)\right)}, \gamma \\
=\frac{k_{0} U\left(C_{\infty}-C_{w}\right)}{v} .
\end{array}
\end{gathered}
$$

where $\lambda$ the non-Newtonian Williamson parameter, $\mathrm{Pr}$ denoted the Prandtl number, Le the Lewis number, $S c$ the Schmidt number, $N c$ the heat capacities ratio, i.e., nanoparticles heat capacity/nanofluid, $N_{b t}$ heat capacity, diffusivity ratio, i.e., Brownian diffusivity/thermophoretic diffusivity, $N b$ the Diffusivity ratio thermophoresis parameter, $E c$ the Eckert number and $\gamma$ is the chemical reaction parameter.

\section{NUMERICAL PROCEDURE}

The numerical solution of the following Eqns. (8)-(10) with corresponding boundary conditions (11) can be obtained by shooting technique. To use the shooting method, first we convert these Eqns. (8)-(10) into a system of first order ODEs. For these purposes, we denote $f$ by $y_{1}, f^{\prime}$ by $y_{2}, f^{\prime \prime}$ by $y_{3}, \theta$ by $y_{4}$ and $\beta$ by $y_{6}$. The coupled nonlinear momentum, heat and concentration equations are converted into system of seven first order ODEs as into the following form:

$$
\begin{array}{lrl}
y_{1}^{\prime}=y_{2}, & y_{1}(0) & =0 \\
y_{2}^{\prime}=y_{3}, & y_{2}(0) & =1 \\
y_{3}^{\prime}=\frac{-y_{1} y_{3}+\left(y_{2}\right)^{2}}{1+\lambda y_{3}} & y_{3}(0) & =r \\
y_{4}^{\prime}=y_{5} & y_{4}(0) & =0 \\
y_{5}^{\prime}=- \text { Pry }_{1} y_{5}-\frac{N c}{L e} y_{5} y_{7}-\frac{N c}{L e \times N_{b t}}\left(y_{5}\right)^{2} & +E c y_{3}^{2} \\
y_{5}(0) & =s \\
y_{6}^{\prime}=y_{7} & y_{6}(0) & =1 \\
y_{7}^{\prime}=- \text { Sey }_{1} y_{7}-\frac{1}{N_{b t}} y_{5}^{\prime}+\text { Lery }_{6} & y_{7}(0) & =t
\end{array}
$$

For solving above system numerically, we replace the domain $(0, \infty]$, by the bounded domain $\left[0, \eta_{\infty}\right]$ where $\eta_{\infty}$ is some suitable real number. In the above system of equations, we have $y_{3}(\eta), y_{5}(\eta)$ and $y_{7}(\eta)$ at $\eta=0$ i.e., $r, s$ and $t$ are missing conditions and are to be chosen such that

$y_{2}\left(\eta_{\infty}, r, s, t\right) \approx 0, y_{4}\left(\eta_{\infty}, r, s, t\right)$ and $y_{6}\left(\eta_{\infty}, r, s, t\right) \approx 0$. 
Finally, the choice of $\eta_{\max }=12$ was more than enough for end condition. The convergence criteria is chosen to be successive value agree up top 3 significant digits.

\section{CODE VALIDATION}

In Table 1 and 2, comparison of Nusselt number for different values of $\boldsymbol{\lambda}, \boldsymbol{L} \boldsymbol{e}, \boldsymbol{N}_{\boldsymbol{b t}}, \boldsymbol{N c}, \boldsymbol{P r}$ is displayed. Furthermore, our findings are compared with the published work of S. Nadeem et al. [16], which show a good agreement of numerical results.

Table 1. Comparison Values of wall temperature gradient $-\theta^{\prime}(0)$

\begin{tabular}{c|c|c|c|c|c|c}
\hline$\lambda$ & \multirow{2}{*}{ Le } & \multirow{2}{*}{$N_{b t}$} & \multirow{2}{*}{$N c$} & \multirow{2}{*}{$\operatorname{Pr}$} & \multicolumn{2}{|c}{$-\theta^{\prime}(0)$} \\
\cline { 5 - 7 } & & & & & $\begin{array}{c}\text { S. Nadeem } \\
{[\mathbf{1 6 ]}}\end{array}$ & $\begin{array}{c}\text { Present } \\
\text { Value }\end{array}$ \\
\hline 0.0 & 4.0 & 2.0 & 0.5 & 0.5 & 0.314 & 0.313593600 \\
\hline 0.2 & & & & & 0.309 & 0.308631400 \\
\hline 0.4 & & & & & 0.302 & 0.302629700 \\
\hline 0.2 & 4.0 & 2.0 & 0.5 & 0.5 & 0.309 & 0.308631400 \\
\hline & 10 & & & & 0.332 & 0.331970600 \\
\hline & 20 & & & & 0.340 & 0.340100600 \\
\hline 0.2 & 4.0 & 0.5 & 0.5 & 0.5 & 0.286 & 0.285833100 \\
\hline & & 1.0 & & & 0.301 & 0.300789200 \\
\hline & & 2.0 & & & 0.309 & 0.308631200 \\
\hline 0.2 & 4.0 & 2.0 & 0.5 & & 0.309 & 0.308631400 \\
\hline & & & 1.0 & & 0.273 & 0.273043200 \\
\hline & & & 2.0 & & 0.213 & 0.212952100 \\
\hline & & & & 0.2 & 0.144 & 0.179527600 \\
\hline & & & & 0.6 & 0.355 & 0.352547300 \\
\hline & & & & 1.2 & 0.588 & 0.586684900 \\
\hline
\end{tabular}

Table 2. Comparison Values of wall nano particle volume fraction gradient $-\beta^{\prime}(0)$

\begin{tabular}{c|c|c|c|c|c}
\hline & \multirow{2}{*}{$\lambda$} & \multirow{2}{*}{$L e$} & $N_{b t}$ & \multirow{2}{*}{$S c$} & \multicolumn{2}{|c}{$-\beta^{\prime}(0)$} \\
\cline { 5 - 6 } & & & & $\begin{array}{c}\text { S. Nadeem } \\
{[\mathbf{1 6 ]}}\end{array}$ & $\begin{array}{c}\text { Present } \\
\text { Value }\end{array}$ \\
\hline 0.0 & 4.0 & 2.0 & 0.5 & 0.833 & 0.834052200 \\
\hline 0.2 & & & & 0.824 & 0.824271200 \\
\hline 0.4 & & & & 0.811 & 0.811198500 \\
\hline 0.2 & 4.0 & 2.0 & 0.5 & 0.824 & 0.824271200 \\
\hline & 10 & & & 0.815 & 0.814918800 \\
\hline & 20 & & & 0.812 & 0.811866000 \\
\hline 0.2 & 4.0 & 0.5 & 0.5 & 0.620 & 0.623315500 \\
\hline & & 1.0 & & 0.751 & 0.751818400 \\
\hline & & 2.0 & & 0.823 & 0.823637800 \\
\hline 0.2 & 4.0 & 2.0 & 0.5 & 0.228 & 0.240325600 \\
\hline & & & 1.0 & 0.475 & 0.473748100 \\
\hline & & & 2.0 & 0.824 & 0.823637900 \\
\hline
\end{tabular}

\section{RESULTS AND DISCUSSION}

This section aims to examine the effect of different parameters $\lambda, P r, L e, N c, N b t, E c$ and $\chi$ (i.e., NonNewtonians Williamson parameter, Prandtl number, Lewis number, heat capacities ratio, i.e., nanoparticles heat capacity/nanofluid, heat capacity, diffusivity ratio, i.e., Brownian diffusivity/thermophoretic diffusivity, Eckert number and Chemical reaction parameter) on dimensionless velocity, temperature and concentration in the form of tables and graphs. Here, we include the conversation on numerical results obtained by shooting technique. Also, the velocity, temperature and concentration profile is plotted in which the influence of different parameters is discussed.

To observe the effects of different parameters on dimensionless velocity $f^{\prime}(\eta)$, dimensionless temperature $\theta(\eta)$ and dimensionless concentration $\beta(\eta)$ graphs are plotted below.

From Figure 1 it is observed that for a nanofluid the velocity as well as the boundary layer thickness decreases with the increase in non-Newtonian parameter $\lambda$.

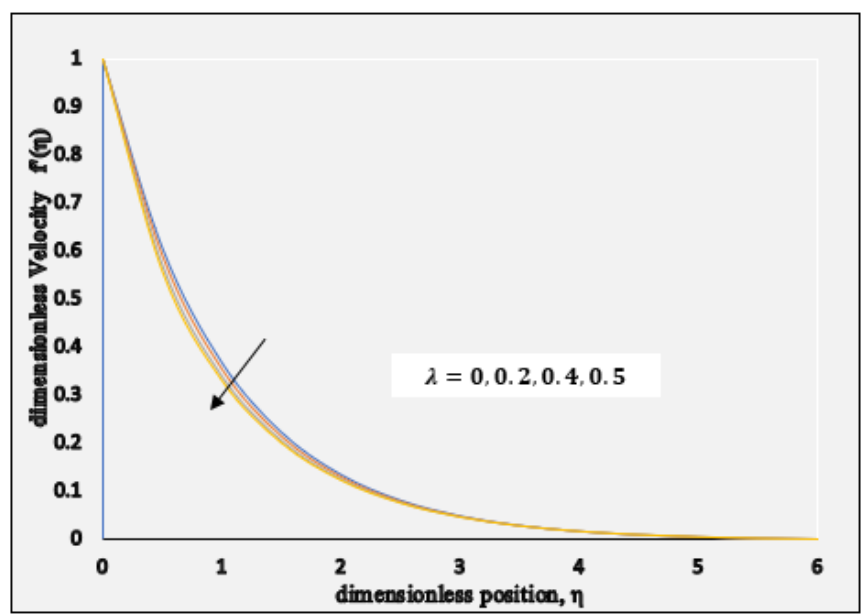

Figure 1. Dimensionless velocity vs $\lambda$ when $\operatorname{Pr}=$ $0.5, N c=0.5, L e=4, N b t=2, S c=2, E c=0.5$ and $\chi=$ 0.2

Figure 2 are the graphical representation which depicts the influence of Prandtl number $\mathrm{Pr}$ on dimensionless temperature and concentration. It is seen that temperature profile reduces for the rising estimations of Prandtl number. Greater the Prandtl number outcomes the lower thermal diffusivity. In this way increment in Prandtl number decreases conduction and henceforth the variation in thermal characteristics increases.

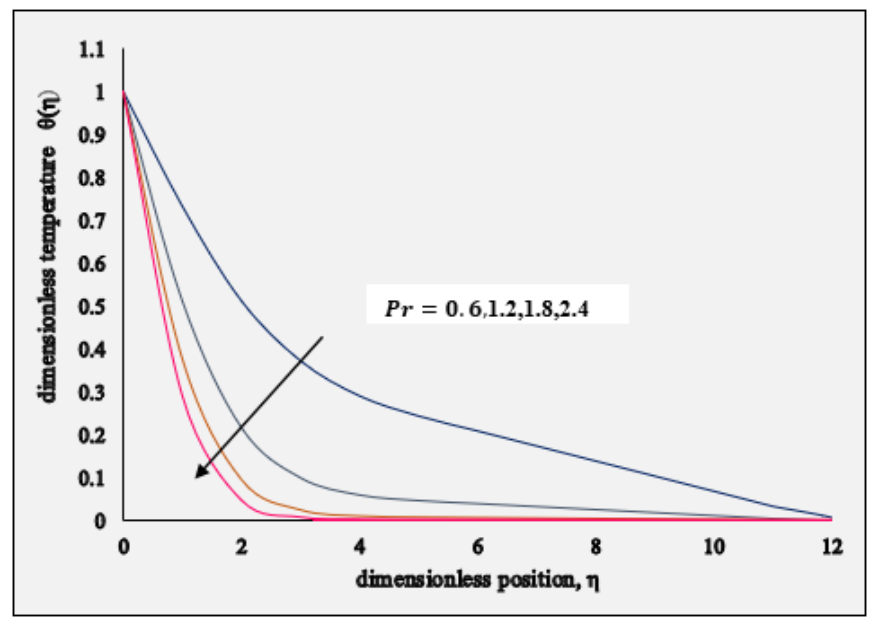

Figure 2. Dimensionless temperature vs $\operatorname{Pr}$ when $\beta=$ $0.2, N c=0.5, L e=4, N b t=2, S c=2, E c=0.5$ and $\chi=$ 0.2

The impact of Le on dimensionless temperature profile $\theta(\eta)$ and concentration profile $\beta(\eta)$ can be seen as in Figures 3 and 4 . From the figures, it is observed that by increasing values of Lewis number temperature decreases and 
concentration as well as the thickness of concentration increases. This is due to the fact that $L e$ physically expresses the respective contribution of rate of thermal diffusion to the rate of species diffusion in the boundary layer regime. As increasing values of Lewis number reduce the thickness of thermal boundary layer and temperature decrease. It also reveals that the concentration gradient at surface of the plate increases.

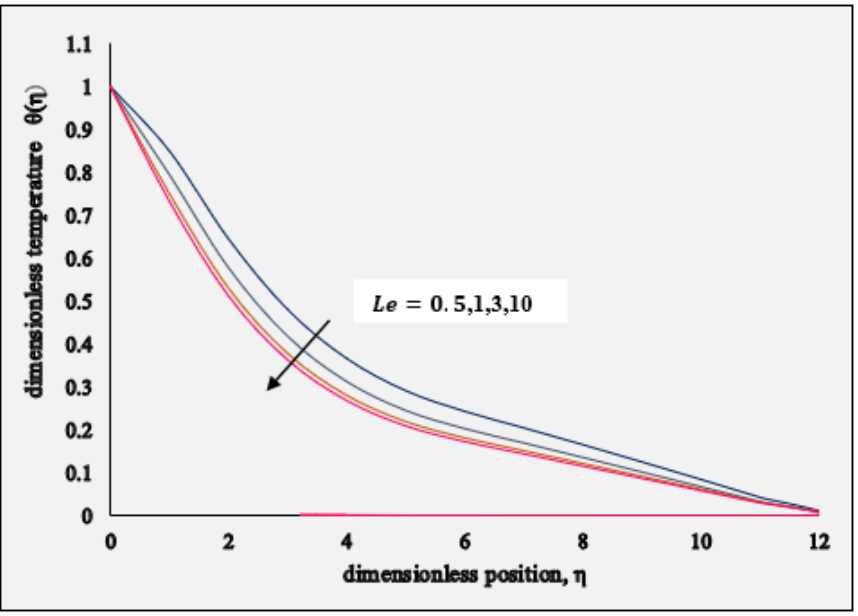

Figure 3. Dimensionless temperature vs $L e$ when $\beta=$ $0.2, N c=0.5, P r=0.5, N b t=2, S c=2, E c=0.5$ and

$$
\chi=0.2
$$

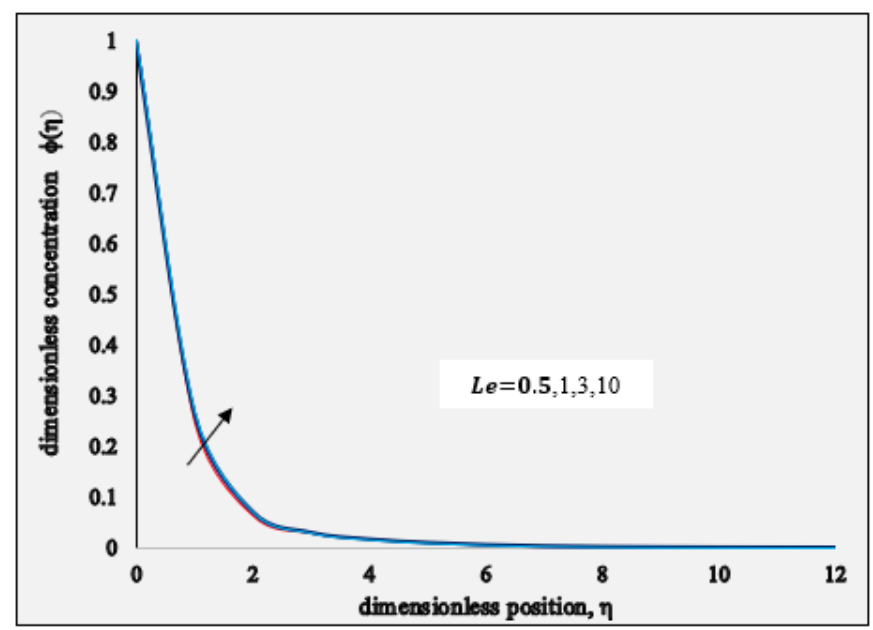

Figure 4. Dimensionless temperature vs $L e$ when $\beta=$ $0.2, N c=0.5, P r=0.5, N b t=2, S c=2, E c=0.5$ and

$$
\chi=0.2
$$

The variation of temperature verses heat capacity ratio parameter $(N c)$ is plotted in figure 5 . Since the heat capacities ratio is equal to the ratio of nanoparticle heat capacity to the nanofluid heat capacity. It is seen that as Nc increases the temperature of the fluid increases.

The effect of $N b t$ on temperature and mass volume friction is shown in figures 6 and 7. Nbt is the ratio of Brownian diffusivity to thermophoretic diffusivity. An increase in $\mathrm{Nbt}$ the temperature of the fluid is decreases as well as same results were found in mass volume friction.

From figure 8 show that the variation of the Schmidt number $(S c)$ to the nanoparticle volume friction. Since Schmidt number is the ratio of the momentum diffusivity to
Brownian diffusivity. It is seen that nanoparticle volume friction decreases with increases the Schmidt number.

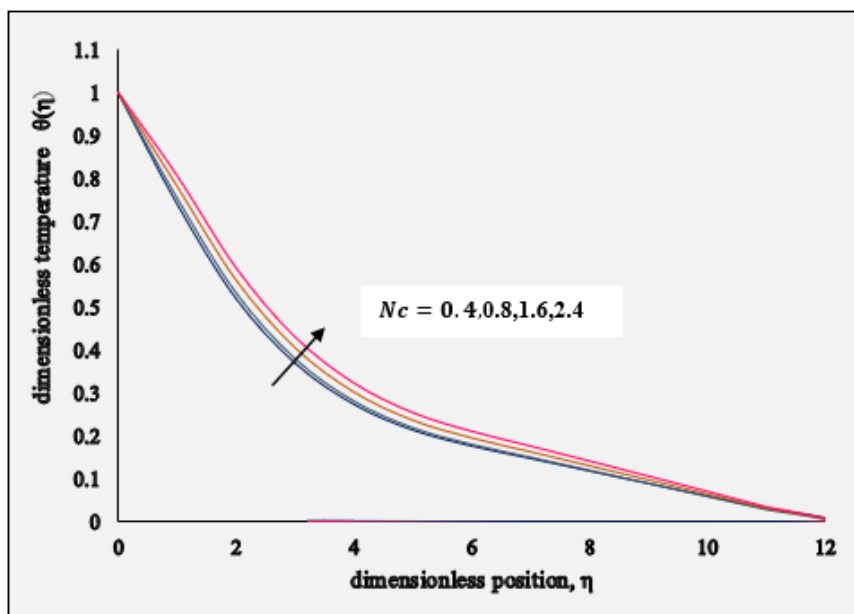

Figure 5. Dimensionless temperature vs $N c$ when $\beta=$ $0.2, L e=4, \operatorname{Pr}=0.5, N b t=2, S c=2, E c=0.5$ and $\chi=$ 0.2



Figure 6. Dimensionless temperature vs $N b t$ when $\beta=$ $0.2, L e=4, \operatorname{Pr}=0.5, N c=2, S c=2, E c=0.5$ and $\chi=0.2$

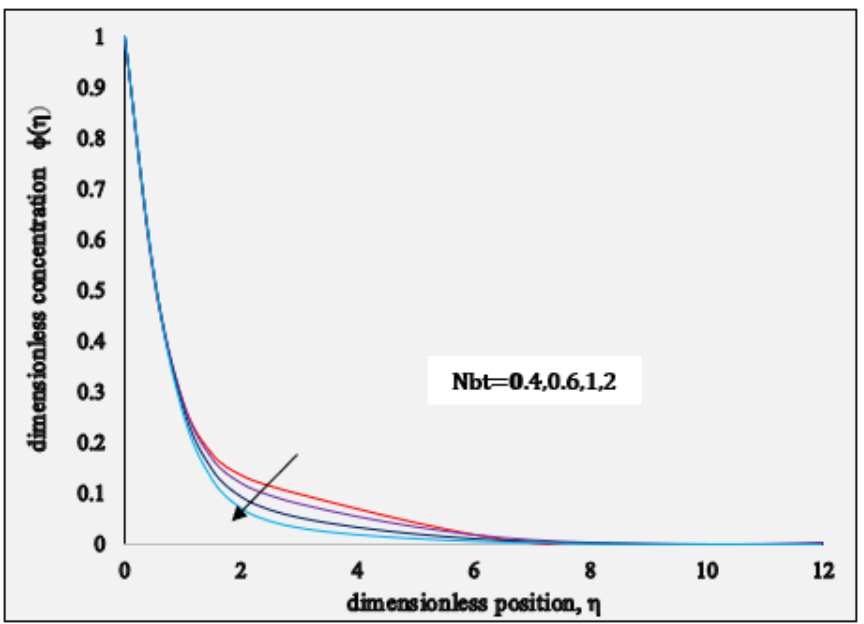

Figure 7. Dimensionless concentration vs $N c$ when $\beta=$ $0.2, L e=4, P r=0.5, N b t=2, S c=2, E c=0.5$ and $\chi=$ 0.2 


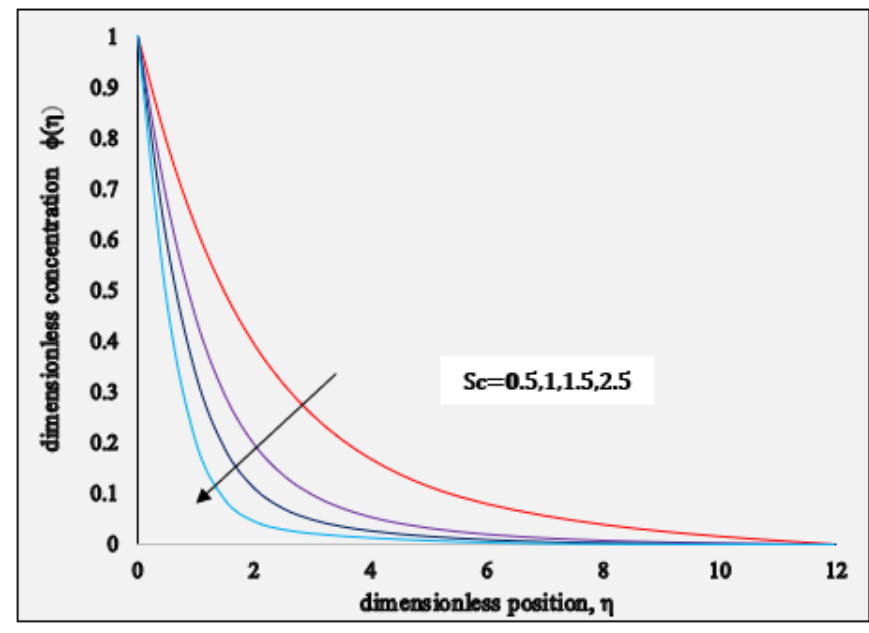

Figure 8. Dimensionless concentration vs $N b t$ when $\beta=$ $0.2, L e=4, \operatorname{Pr}=0.5, N c=2, N b t=2, E c=0.5$ and $\chi=$ 0.2



Figure 9. Dimensionless temperature vs $E c$ when $\beta=$ $0.2, L e=4, P r=0.5, N c=2, N b t=2, N b t=2$ and $\chi=$ 0.2

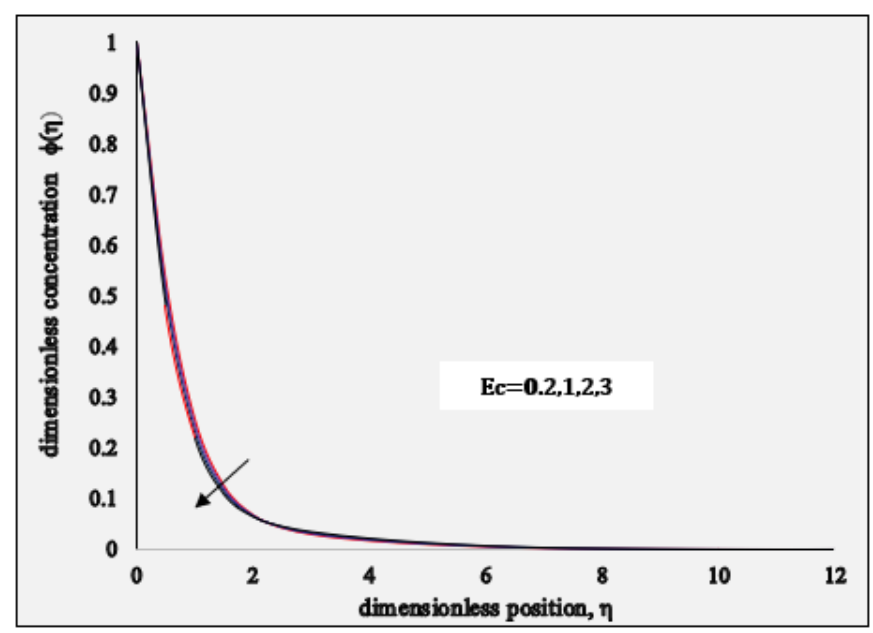

Figure 10. Dimensionless concentration vs $E c$ when $\beta=$ $0.2, L e=4, \operatorname{Pr}=0.5, N c=2, N b t=2, N b t=2$ and $\chi=$ 0.2

Figure 9 and 10 shows the effect of viscous dissipation on temperature and concentration profile. It is observed that increase in dissipation also increases temperature whereas concentration profile decreasing.

Figure 11 and 12 explains the influence of the chemical reaction parameter on the profile of concentration. It is noted that increasing values of chemical reaction parameter concentration as well as the thickness of concentration decrease. It is because of the fact that the chemical reaction in this system results in chemical dissipation and therefore results in decrease in the profile of concentration. The most significant influence is that chemical reaction tends to decrease the overshoot in the concentration profiles and their associated boundary layer.

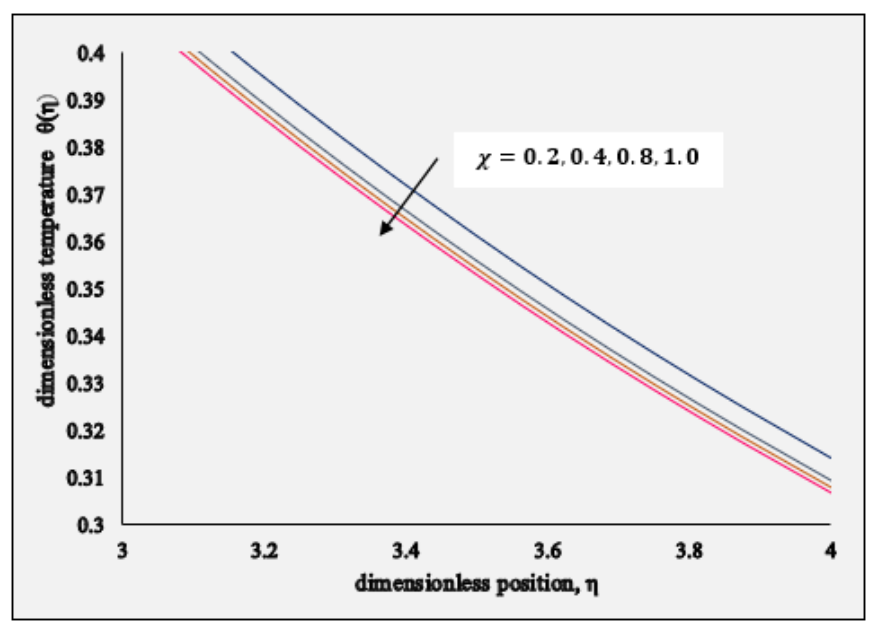

Figure 11. Dimensionless temperature vs $E c$ when $\beta=$ $0.2, L e=4, P r=0.5, N c=2, N b t=2, N b t=2$ and $E c=$ 0.2

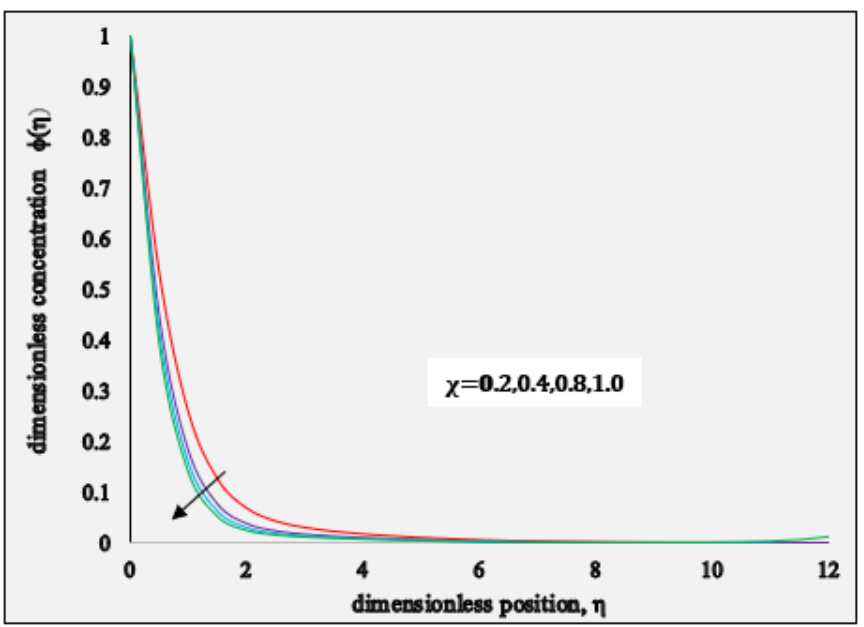

Figure 12. Dimensionless concentration vs $E c$ when $\beta=$ $0.2, L e=4, \operatorname{Pr}=0.5, N c=2, N b t=2, N b t=2$ and $E c=$ 0.2

\section{CONCLUSION}

After a thorough investigation, we have reached the following concluding observation.

- Fluid velocity decreases with an increase in the nonNewtonian Williamson parameter.

* Due to an increase in the chemical reaction parameter, the temperature field as well as concentration profile decreases. 
* The influence of diffusivity ratio parameter or heat capacities ratio parameter reduces the heat transfer coefficient.

* Energy profile $\theta$ increases by enlarging $E c$.

\section{Acknowledgement}

The authors would like to thanks to Prof. Koneru S.R., Retired Professor, Department of Mathematics, IIT Bombay for his support throughout this research work.

\section{References}

[1] Prandtl L. (1904). Uber flussigkeitsbewegung bei sehr kleiner reibung. Verhandl. 3rd Int. Maths. Kongr, Heideberg, Leipzig, 1905.

[2] Motsumi GT, Makinde O. (2012). Effects of thermal radiation and viscous dissipation on boundary layer ow of nanofluids over a permeable moving at plate. Physica Scripta 86(4): 045003. https://doi.org/10.1088/00318949/86/04/045003

[3] Ibrahim W, Makinde OD. (2013). The effect of double stratification on boundary layer flow and heat transfer of nanofluid over a vertical plate. Computers \& Fluids 86: 433-441. https://doi.org/10.1016/j.compfluid.2013.07.029

[4] Makinde OD. (2012). Analysis of Sakiadis flow of nanofluids with viscous dissipation and Newtonian heating. Applied Mathematics and Mechanics 33(12): 1545-1554.

[5] Daniel Makinde O. (2013). Computational modeling of nanofluids ow over a convectively heated unsteady stretching sheet. Current Nanoscience 9(5): 673-678. https://doi.org/10.2174/15734137113099990068

[6] Sakiadis B. (1961). Boundary-layer behavior on continuous solid surfaces: I. boundary-layer equations for two-dimensional and axisymmetric flow. AIChE Journal $7(1)$ : 26-28. https://doi.org/10.1002/aic.690070108

[7] Choi SUS, Eastman JA. (1995). Enhancing thermal conductivity of fluids with nanoparticles. https://www.researchgate.net/publication/236353373 E nhancing_thermal_conductivity_of_fluids_with_nanopa rticles, accessed on January 1995.

[8] Malvandi A, Ganji DD. (2014). Effects of nanoparticle migration on force convection of alumina/water nanofluid in a cooled parallel-plate channel. Adv. Powder Technol 25(4): 1369-1375. https://doi.org/10.1016/j.apt.2014.03.017

[9] Khanafer K, Vafai K. (2011). A critical synthesis of thermophysical characteristics of nanofluids. International Journal of Heat and Mass Transfer 54(19): 4410-4428.

https://doi.org/10.1016/j.ijheatmasstransfer.2011.04.048

[10] Masuda H, Ebata A, Teramae K, Hishinuma N. (1993). Alteration of thermal conductivity and viscosity of liquid by dispersing ultra-fine particles dispersion of $\mathrm{Al}_{2} \mathrm{O}_{3}$; $\mathrm{SiO}_{2}$ and $\mathrm{TiO}_{2}$ ultra-fine particles. Netsu Bussei 7(4): 227-233. https://doi.org/10.2963/jjtp.7.227

[11] Buongiorno J. (2006). Convective transport in nanofluids. Journal of Heat Transfer 128(3): 240-250. https://doi.org/10.1115/1.2150834

[12] Mehrez Z, Bouterra M, El Cafsi A, Belghith A. (2013). Heat transfer and entropy generation analysis of nanofluids flow in an open cavity. Computers \& Fluids 88: 363-373. https://doi.org/10.1016/j.compfluid.2013.09.026

[13] Vajravelu K. (2001). Viscous flow over a nonlinearly stretching sheet. Applied mathematics and computation. Applied Mathematics and Computation 124(3): 281-288. https://doi.org/10.1016/S0096-3003(00)00062-X

[14] Gebhart B, Mollendorf J. (1969). Viscous dissipation in external natural convection flows. J. Fluid Mechanics, 38(01): 97-107. https://doi.org/10.1017/S0022112069000061

[15] Duwairi HM. (2005). Viscous and Joule heating effects on forced convection ow from radiate isothermal porous surfaces. Int. J. Numerical Methods for Heat \& Fluid Flow 15(5): 429-440. https://doi.org/10.1108/09615530510593620

[16] Nadeem S, Hussain ST. (2014). Flow and heat transfer analysis of Williamson nanofluid. Appl Nanosci. 4(8): 1005-1012. 